\title{
Erratum to: Schematic Processing: A Comparison of Clinically Depressed, Dysphoric, and Nondepressed College Students
}

Lisa Halberstadt • Gerald J. Haeffel •

Lyn Y. Abramson - Basabi R. Mukherji •

Gerald I. Metalsky $\cdot$ Benjamin M. Dykman

Published online: 7 January 2011

(C) Springer Science+Business Media, LLC 2011

Erratum to: Cogn Ther Res (2008) 32:843-855

DOI 10.1007/s10608-007-9153-y

The affiliation for one of the co-authors L. Halberstadt is incorrect on page 843 in the original publication. The correct affiliation should be Department of Psychiatry, Virginia Commonwealth University, Virginia, USA.

The online version of the original article can be found under doi:10.1007/s10608-007-9153-y.

L. Halberstadt

Department of Psychiatry, Virginia Commonwealth University,

Virginia, USA

G. J. Haeffel ( $\square)$

Department of Psychology, University of Notre Dame,

118 Haggar Hall, Notre Dame, IN 46556, USA

e-mail: ghaeffel@nd.edu

L. Y. Abramson · B. M. Dykman

Department of Psychology, University of Wisconsin-Madison,

Madison, WI, USA

B. R. Mukherji

Department of Psychology, SUNY-Old Westbury,

Old Westbury, NY, USA

G. I. Metalsky

Department of Psychology, Lawrence University,

Appleton, WI, USA 